Original Research Article

\title{
Hyponatremia in children of 2 months to 5 years of age with community acquired pneumonia and its correlation with severity of illness and outcome
}

\author{
C. K. Praneetha ${ }^{1}$, Ahirrao V. S. ${ }^{2}$, K. Srinivasa ${ }^{3}$, R. Premalatha ${ }^{4}$, B. Ravichander ${ }^{5}$ \\ ${ }^{1}$ Dr. C. K. Praneetha, Pediatrics, Senior Registrar, Columbia Asia Hospital, Sarjapur Road, Bangalore, ${ }^{2}$ Dr. Ahirrao Varsha \\ Suresh, Associate Professor, ${ }^{3}$ Dr. K. Srinivasa, Professor, ${ }^{4}$ Dr. R. Premalatha, Head of Department of Pediatrics, \\ ${ }^{5}$ Dr. B. Ravichander, Principal and Professor; ${ }^{2,3,4,5}$ authors are affiliated with Department of Pediatrics MVJ Medical College \\ and Research Hospital, Bangalore, Karnataka, India.
}

Corresponding Author: Dr. Ahirrao Varsha Suresh, Associate Professor, Department of Pediatrics, MVJ Medical College and Research Hospital, Bangalore, Karnataka, India. Email: drvarsha2006@yahoo.co.in

\begin{abstract}
Introduction: Hyponatremia is a common electrolyte imbalance observed in children with pneumonia. Presence of hyponatremia may increase the morbidity and mortality in pneumonia. The purpose of the study was to find the frequency of hyponatremia in 2 months to 5 years old children hospitalized with pneumonia and to correlate the hyponatremia with the severity of pneumonia. Methods: This prospective observational study involved 122 children of 2 months to 5 years, admitted in tertiary care hospital from 2016 to 2018 with community acquired pneumonia. Subjects were classified as pneumonia and severe pneumonia according to WHO criteria. Relevant demographic, clinical data and outcome of the patients were noted. Serum sodium was analyzed and was correlated with severity of pneumonia. Results: Out of 122 children included in this study, 73 were boys and 49 were girls. Hyponatremia was found in $43.5 \%$ of children with community acquired pneumonia. Mild hyponatremia was the commonest and seen in $66 \%$ children. $68 \%$ of children with severe pneumonia had hyponatremia compared to $23 \%$ children with pneumonia ( $p$ value $<0.01$ ). $48 \%$ of patients with hyponatremia compared to $26 \%$ of patients without hyponatremia had hospital stay more than 7 days which was statistically significant. Mortality was $12 \%$ in children with hyponatremia compared to $1.5 \%$ with normonatremia. Conclusion: Hyponatremia is a common electrolyte imbalance found in community acquired pneumonia and more commonly seen in severe pneumonia. Hyponatremia is associated with prolonged hospital stay and increased mortality.
\end{abstract}

Keywords: Children, Hyponatremia, Mortality, Pneumonia.

\section{Introduction}

Pneumonia is a significant cause of mortality in childhood throughout the world particularly in developing countries [1]. Pneumonia accounts for $15 \%$ of all deaths of children under 5 years old, killing 808694 children in 2017 [2]. According to UNICEF data updated on December 2018, India has a under five mortality rates of 39.4 per 1,000 live births [3]. Pneumonia is a frequent cause of hospitalization among children and is associated with several complications. One of the common electrolyte abnormalities seen in pneumonia is hyponatremia. Hyponatremia is defined as a serum sodium concentration of less than $135 \mathrm{mq} / \mathrm{dl}$ [4]. Various studies done in western countries have reported a high prevalence of hyponatremia in community acquired pneumonia. Hyponatremia could result from a sodium deficit or surplus of water.

Manuscript received: $30^{\text {th }}$ October 2019

Reviewed: $10^{\text {th }}$ November 2019

Author Corrected: $16^{\text {th }}$ November 2019

Accepted for Publication: $20^{\text {th }}$ November 2019
Exact cause of hyponatremia in community acquired pneumonia is still being studied. The basic pathophysiology is thought to be due to stress induced release of antidiuretic hormone $(\mathrm{ADH})$. This inappropriate production of $\mathrm{ADH}$ produces water retention and hence euvolemic hyponatremia leading to SIADH [5-8].

Hyponatremia has also been documented as a marker of severe illness and increased mortality in few studies [9]. However, Indian studies on hyponatremia in community acquired pneumonia in children are few.

Hence this study was done to find out the frequency of hyponatremia in community acquired pneumonia in under 5 children hospitalized in rural tertiary setting and to correlate the serum sodium levels to severity of pneumonia. 
Original Research Article

\section{Objectives of the study}

1) To find out the frequency of hyponatremia in community acquired pneumonia.

2) To correlate hyponatremia with severity of pneumonia and outcome.

\section{Methodology}

Type of study: Prospective observational study

Settings: Pediatric department of MVJ Medical college and Research Hospital, Hoskote, Bangalore.

Duration: Over a period of 2 years from 2016 to 2018.

Sample Size: Sample size of 122 was calculated using the formula $n=4 p q /(e)^{2}$.

Inclusion criteria: Children with age 2 months to 5 years, admitted in the hospital and diagnosed clinically as community acquired pneumonia according WHO criteria (presence of fever, cough, tachypnea for the age) [10] were included in the study.

Exclusion criteria: Children with preexisting respiratory and cardiac morbidity, with associated diarrhea, on medications and diseases affecting sodium homeostasis and with pneumonia due to nosocomial infection or aspiration were excluded.

Data collection procedure: A total of 122 children were included in the study. As per revised WHO ARI guidelines, according to severity, subjects were classified as having pneumonia or severe pneumonia [10]. At the time of admission, serum sodium was sent and analyzed using automated analyzer that uses ISE (ion selective electrode) technology. Subject's clinical data including age, sex, requirement of ventilation, duration of hospital stay and the final outcome (death or discharged) were recorded in all patients. Serum sodium concentration $<135 \mathrm{mEq} / \mathrm{L}$ was considered as hyponatremia.

Hyponatremia was classified as mild, moderate and severe as follows: Serum sodium of 131 to $134 \mathrm{mEq} / \mathrm{L}$ was considered as mild, 126 to $130 \mathrm{mEq} / \mathrm{L}$ as moderate and equal to or less than $125 \mathrm{mEq} / \mathrm{L}$ as severe hyponatremia. Hyponatremia was correlated with age, sex, severity of community acquired pneumonia, shock, requirement of ventilation, duration of hospital stay and outcome (death or improved).

Data analysis: Data was entered in the Microsoft Excel spread sheet and analyzed. The statistical software namely SAS 9.2, SPSS 15.0 Stata 10.1, Medcal 9.0.1, Systat 12.0 and R environment ver 2.11.1 were used for analysis of data. The primary and secondary outcomes were expressed as percentage. Chi Square test was used to determine the association between outcome variable and dependent variable. $\mathrm{P}$ value $</=0.01$ was considered strongly significant. P value between $0.05-0.01$ was considered moderately significant.

Ethical consideration: Ethical clearance was obtained from the ethical committee of the institution.

\section{Results}

122 children admitted with pneumonia were included in the study. 94 (77\%) patients were in 2 months to 2 years of age group and $28(23 \%)$ patients were in $2-5$ years of age group. 73 patients (63\%) were males and 49 patients (40\%) were females. 68 patients $(56 \%)$ had pneumonia and 54 patients $(44 \%)$ had severe pneumonia.

Frequency of hyponatremia: Out of 122 patients included in the study, $53(43.5 \%)$ patients with community acquired pneumonia had hyponatremia. According to severity, hyponatremia was divided into three categories: mild, moderate and severe. Out of 53 children with hyponatremia, majority of the patients i.e. 35 children (66\%) had mild hyponatremia, followed by moderate hyponatremia in $11(21 \%)$ patients and severe hyponatremia in $7(13 \%)$ patients.

Correlation of Hyponatremia with Age, Gender and Nutrition: Age wise, pneumonia patients were grouped into following age groups: 2 months to 2 years and 2 to 5 years. 42 patients out of 94 patients ( $42 \%)$ in the age group of 2 months to 2 year and 13 out of 28 patients $(46 \%)$ in the age group of 2-5 years developed hyponatremia. There was no statistically significant difference noted in the frequency of hyponatremia in both the age groups ( $p$ value $>0.05$ ).

In the present study, 73 were males and 49 were females. $40 \%$ of males with pneumonia had hyponatremia compared to $49 \%$ of females with pneumonia. Hyponatremia was more commonly seen in females compared to males, however there was no statistically significant difference ( $\mathrm{P}$ value $>0.05$ ).

Children were categorized according to nutritional status as normal and malnourished. 37 patients out of 92 patients with normal nutrition (40\%) had hyponatremia compared to 16 out of 30 patients with malnutrition (53\%) had hyponatremia. It was found that hyponatremia was found in both the groups with normal nutrition and malnutrition and there was no statistically significant difference $(\mathrm{P}>0.05)$. 
Original Research Article

Correlation of hyponatremia with severity of pneumonia: According to revised WHO classification, classified illness was divided into 2 severity categories: Pneumonia and Severe Pneumonia. Hyponatremia was correlated with severity of illness (Table 1).

Table-1: Correlation of hyponatremia with severity of pneumonia.

\begin{tabular}{|c|c|c|c|c|}
\hline $\begin{array}{c}\text { WHO } \\
\text { classification of Pneumonia }\end{array}$ & $\begin{array}{c}\text { Total number of } \\
\text { children } \\
(\mathbf{n = 1 2 2})\end{array}$ & $\begin{array}{c}\text { Hyponatremia } \\
(\mathbf{n = 5 3 )}\end{array}$ & $\begin{array}{c}\text { Normonatremia } \\
(\mathbf{n = 6 9 )}\end{array}$ & $\begin{array}{c}\text { P } \\
\text { Value }\end{array}$ \\
\hline Pneumonia & 68 & $16(23 \%)$ & $52(77 \%)$ & \multirow{2}{*}{$\mathbf{0 . 0 0 1}$} \\
\cline { 1 - 3 } Severe pneumonia & 54 & $37(68 \%)$ & $17(32 \%)$ & \\
\hline Total & 122 & 53 & 69 & \\
\hline
\end{tabular}

37 out of 54 patients $(68 \%)$ with severe pneumonia had hyponatremia compared to 16 out of 68 patients (23\%) with pneumonia. Hyponatremia was more commonly seen in severe pneumonia group when compared to the pneumonia group. The difference was found to be statistically significant $(\mathrm{p}<0.01)$.

Correlation of severity of pneumonia with severity of hyponatremia: Severity of hyponatremia was correlated with severity of pneumonia (Table 2).

Table-2: Correlation of Severity of pneumonia with severity of hyponatremia.

\begin{tabular}{|c|c|c|c|c|c|}
\hline \multirow{2}{*}{$\begin{array}{c}\text { WHO } \\
\text { classification of } \\
\text { Pneumonia }\end{array}$} & \multicolumn{3}{|c|}{ Hyponatremia } & \multirow{2}{*}{$\begin{array}{c}\text { Total number of } \\
\text { children with } \\
\text { hyponatremia }(n=53)\end{array}$} & \multirow[t]{2}{*}{ P Value } \\
\hline & Mild & Moderate & Severe & & \\
\hline Pneumonia & $15(94 \%)$ & 0 & $1(6 \%)$ & 16 & \multirow{3}{*}{0.016} \\
\hline Severe pneumonia & $20(54 \%)$ & $11(30 \%)$ & $6(16 \%)$ & 37 & \\
\hline Total & 35 & 11 & 7 & 53 & \\
\hline
\end{tabular}

$94 \%$ of patients in pneumonia group and $54 \%$ of patients in severe pneumonia group had mild hyponatremia. It was seen that mild hyponatremia was the commonest in both the pneumonia and severe pneumonia group. Moderate and severe hyponatremia was more commonly seen in the severe pneumonia group compared to pneumonia group. The difference was statistically significant $(\mathrm{P}$ value $=0.01)$.

Correlation of Hyponatremia with Shock and mechanical ventilation:

Hyponatremia was correlated with presence of shock (Table3).

Table-3: Correlation of hyponatremia with shock.

\begin{tabular}{|c|c|c|c|c|}
\hline Shock & $\begin{array}{c}\text { Normonatremia } \\
(\mathbf{n = 6 9 )}\end{array}$ & $\begin{array}{c}\text { Hyponatremia } \\
(\mathbf{n = 5 3 )}\end{array}$ & $\begin{array}{c}\text { Total number of } \\
\text { children }(\mathbf{n = 1 2 2})\end{array}$ & P Value \\
\cline { 1 - 4 } Absent & $67(67 \%)$ & $33(33 \%)$ & 100 & \multirow{2}{*}{$\mathbf{0 . 0 0 0 1}$} \\
\cline { 1 - 3 } Present & $2(9 \%)$ & $20(91 \%)$ & 122 & \\
\hline Total & 69 & 53 & 22 & \\
\hline
\end{tabular}

$91 \%$ of patients with shock had hyponatremia compared to $33 \%$ of patients without shock. The difference was statistically significant $(\mathrm{P}<0.01)$. Hyponatremia was also correlated with requirement of mechanical ventilation (table 4).

Table-4: Correlation of hyponatremia with mechanical ventilation.

\begin{tabular}{|c|c|c|c|c|}
\hline $\begin{array}{c}\text { Mechanical } \\
\text { ventilation }\end{array}$ & $\begin{array}{c}\text { Normonatremia } \\
(\mathbf{n = 6 9 )}\end{array}$ & $\begin{array}{c}\text { Hyponatremia } \\
(\mathbf{n}=\mathbf{5 3})\end{array}$ & $\begin{array}{c}\text { Total number of } \\
\text { patients }(\mathbf{n}=\mathbf{1 2 2})\end{array}$ & P Value \\
\hline Not required & $67(63 \%)$ & $40(37 \%)$ & 107 & 0.0001 \\
\hline Required & $2(13 \%)$ & $13(87 \%)$ & 15 & \\
\hline Total & $\mathbf{6 9}$ & $\mathbf{5 3}$ & $\mathbf{1 2 2}$ \\
\hline
\end{tabular}


Original Research Article

Mechanical ventilation was required by $15(12 \%)$ patients. $87 \%$ of patients requiring mechanical ventilation compared to $37 \%$ of patients not requiring mechanical ventilation had hyponatremia. Hyponatremia was more commonly seen in patients requiring mechanically ventilation. The difference was statistically significant $(\mathrm{P}$ value $<0.01)$.

Correlation of Hyponatremia to Duration of hospital Stay and Outcome:

Hyponatremia in survived patients was correlated to duration of hospital stay (Table 5).

Table-5: Correlation of hyponatremia to duration of hospital stay.

\begin{tabular}{|c|c|c|c|c|}
\hline $\begin{array}{c}\text { Duration of Hospital } \\
\text { stay }\end{array}$ & $\begin{array}{c}\text { Normonatremia } \\
(\mathbf{n = 6 8})\end{array}$ & $\begin{array}{c}\text { Hyponatremia } \\
(\mathbf{n}=\mathbf{4 8})\end{array}$ & $\begin{array}{c}\text { Total number of survived } \\
\text { patients(n=114) }\end{array}$ & $\begin{array}{c}\text { P } \\
\text { Value }\end{array}$ \\
\hline$<7$ days & $50(74 \%)$ & $24(52 \%)$ & 74 & \multirow{2}{*}{$\mathbf{0 . 0 1}$} \\
\hline$>7$ days & $18(26 \%)$ & $22(48 \%)$ & 40 & \\
\hline Total & 68 & 46 & 114 & \\
\hline
\end{tabular}

$48 \%$ of patients with hyponatremia compared to $26 \%$ of patients without hyponatremia had hospital stay more than 7 days. Children with hyponatremia had prolonged duration of hospital stay compared to children without hyponatremia. The difference was statistically significant.

Hyponatremia in community acquired pneumonia was correlated with mortality (Table 6).

Table-6: Correlation of hyponatremia to outcome.

\begin{tabular}{|c|c|c|c|c|}
\hline Outcome & $\begin{array}{c}\text { Normonatremia } \\
(\mathbf{n = 6 9 )}\end{array}$ & $\begin{array}{c}\text { Hyponatremia } \\
(\mathbf{n}=\mathbf{5 3})\end{array}$ & $\begin{array}{c}\text { Total number of children } \\
(\mathbf{n = 1 2 2})\end{array}$ & P Value \\
\cline { 1 - 4 } Improved & $68(98.5 \%)$ & $46(87 \%)$ & 114 & \multirow{2}{*}{$\mathbf{0 . 0 1}$} \\
\hline Death & $1(1.5 \%)$ & $7(13 \%)$ & 8 & 122 \\
\hline Total & 69 & 53 &
\end{tabular}

Mortality in patients with community acquired pneumonia was 6.5\% (8/122 patients). Mortality was $13 \%$ in patients with hyponatremia compared to $1.5 \%$ in patients with normonatremia. The difference was statistically significant $(\mathrm{P}=0.016)$.

\section{Discussion}

Pneumonia is one of the common causes of hospital admission of children. Hyponatremia is commonly observed electrolyte abnormality in them and is commonly seen to be associated with high morbidity and mortality. So, the frequency of hyponatremia was studied in community acquired pneumonia and its association with severity of illness, duration of hospital stay and mortality.

In the present study, $42 \%$ of children were in age group of 2 months to 2 years and $46 \%$ of children were in the age group of 2 to 5 years. Serious infections including Pneumonia are commoner in less than 2 years of age group because of waning protective passive immunity by maternal antibodies and their immature immune system. Among 122 children included in the study, 73 were males $(60 \%)$ and $49(40 \%)$ were females. This distribution is similar to studies done by Mandal et al [11] and Duru et al [12] showing $62 \%$ and $57 \%$ males respectively in their studies. In the present study, hyponatremia was seen in $43.5 \%$ of children with community acquired pneumonia. Studies done by Don M et al [13] and Otheo et al [14]. showed almost similar frequency of hyponatremia in pneumonia i.e. $45.4 \%$ and $39.7 \%$ respectively. Indian study done by Chaitra et al [15] also found hyponatremia in $47.2 \%$ of children with pneumonia. However, some studies done in India, showed hyponatremia in $21-27 \%$ of patients with pneumonia $[11,16]$. In a study done in India by Mandal et al [11] recorded hyponatremia in $21 \%$ of pneumonia patients and in a study done at PGI Chandigarh, $27 \%$ of patients had hyponatremia [16].

Age, sex and nutritional status had no correlation with occurrence of hyponatremia in the present study. This was comparable to study done by Don $\mathrm{M}$ et al [13]. In the present study, mild hyponatremia was the commonest and was seen in $66 \%$ of children with hyponatremia. Only $21 \%$ and $13 \%$ had moderate and severe hyponatremia respectively. This was comparable to the study done by Mandal et al [11] and Nair et al [17]. Studies done by Mandal et al [11] and Don $M$ et al [13] reported mild hyponatremia in $81 \%$ and $92 \%$ of patients with hyponatremia respectively. Even the study done by Nair et al [17] showed only $4.1 \%$ of patients with community acquired pneumonia had serum sodium level $<130 \mathrm{mEq} /$ 


\section{Original Research Article}

L. In the present study, hyponatremia was more commonly seen in severe pneumonia group than pneumonia group. $70 \%$ of patients in severe pneumonia group had hyponatremia against $30 \%$ of patients in pneumonia group with $P$ value $<0.01$. It was observed in the present study that mild hyponatremia was the commonest in both pneumonia and severe pneumonia group. However, severe hyponatremia was more commonly associated with severe pneumonia. $16 \%$ of patients in severe pneumonia group had severe hyponatremia compared to $6 \%$ of patients in pneumonia group.

Hyponatremia was also more commonly seen in patients with shock (91\%) compared to patients without shock $(9 \%)$ and patients requiring mechanical ventilation $(87 \%)$ than in children not requiring mechanical ventilation $(38 \%)$. Both the presence of shock at the time of admission and requirement of mechanical ventilation suggest more severe illness. Most probably significant association of hyponatremia with shock and requirement of mechanical ventilation is because of severe nature of the illness. Similarly, study done by Don M et al [13] showed that hyponatremia was associated with severity of community acquired pneumonia assessed by fever, need of hospitalization and serum nonspecific inflammatory markers and this was statistically significant with $P$ value $<0.01$.

In the present study, hyponatremia was significantly associated with prolonged hospital stay ( $>7$ days) i.e. $48 \%$ of survived patients with hyponatremia had prolonged hospital stay compared to $26 \%$ without hyponatremia. Mortality was significantly high i.e. $13 \%$ among patients with hyponatremia compared to $1.5 \%$ in patients without hyponatremia $(\mathrm{p}<0.001)$. In a similar study done by Karki $\mathrm{L}$ et al [18] reported that hyponatremia at admission was significantly associated with a longer duration of hospital stay and higher death rate. In a study done by Singhi et al [16] on frequency and significance of electrolyte abnormalities in pneumonia, 4/100 children with pneumonia died and all four of them had a serum sodium concentration less than or equal to $125 \mathrm{mmol} / \mathrm{L}$ which persisted till death and concluded that presence of severe hyponatremia was associated with three-fold increase in risk of death. Similar results are also seen in study done by Guru Swamy et al [19]

Recently, few studies are being done to find out the exact cause of hyponatremia in community acquired pneumonia. Swart RM et al [20] in their article on hyponatremia and inflammation mentioned data supporting a role in the non osmotic release of vasopressin and thought that this mechanism may play role in clinically significant forms of hyponatremia. However, Tagarro A et al [21] in their study to determine the proportion of syndrome of inappropriate antidiuretic hormone (SIADH) secretion among patients with CAP with hyponatremia found that true SIADH is a rare event in patients with CAP with hyponatremia but has a good correlation with inflammatory markers. Hausman-Kedem M et al [22] in their study concluded that B-type natriuretic peptide (BNP) is unlikely to play a causative role in the mechanism of hyponatremia in community acquired pneumonia. However, whatever is the cause of hyponatremia in community acquired pneumonia, various studies including the present study have consistently shown hyponatremia being a common electrolyte imbalance in community acquired pneumonia and is associated with severe illness and increase in the morbidity and mortality. The major limitation of the present study was the cause of hyponatremia in pneumonia not studied.

\section{Conclusions}

Hyponatremia is commonly seen in children with community acquired pneumonia with incidence of $43.5 \%$ in the present study and is more common in severe pneumonia. Mild hyponatremia is the commonest form of hyponatremia seen in community acquired pneumonia. Hyponatremia is significantly associated with prolonged hospital stay and increased mortality.

\section{What this study adds to the existing knowledge?}

Serum electrolytes should be measured in the hospitalized children with pneumonia and presence of hyponatremia at the time of admission will be helpful in predicting morbidity and mortality in children with pneumonia.

\section{Author's contribution}

Dr. Praneetha CK collected and analysed the data under the guidance of Dr. Ahirrao Varsha Suresh. Dr. Ahirrao Varsha Suresh interpreted the results and wrote the manuscript. Dr. Srinivasa, Dr. Premlatha and Dr. Ravichander provided critical feedback and helped shape the research, analysis and manuscript.

Funding: No funding sources

Conflict of interest: None declared

Ethical Approval: This study was approved by the Institutional Ethics Committee

\section{References}

1. Sandora T, Sectish T. Community acquired pneumonia. In: Kliegman RM, Stanton BF, Geme JWS, Schor NF, Behrman RE, editors. Nelson textbook of paediatrics. $19^{\text {th }}$ ed. Philadelphia: Elsevier; 2011. p. 1474-1479.Vol (2). 


\section{Original Research Article}

2. World Health Organization. Pneumonia. Fact sheet. Updated on 2 August 2019 (internet). WHO; 2019 Aug. Available at : http:// www. who.int/en/news-room/factsheets / detail/ pneumonia.

3. Unicef. Unicef data: India- Demographics, Health \& Infant Mortality (internet). Updated on 2018 Dec. Available at: https://data.unicef.org/country//Ind/.

4. Greenbaum LA. Electrolyte and Acid Base Disorders. In: Kliegman RM, StantonBF, SchorNF, St.GemeJW (Eds). Nelson Textbook of Paediatrics. $20^{\text {th }}$ ed. Philadelphia: Elsevier ;2016.p.350.(International Edition ).

5. Howard Trachtman MD. Sodium and water homeostasis. Pediatr Clin North Am.1995;42(6):13431363.doi:https://doi.org/10.1016/S0031-3955(16)40088-X.

6. Didlier Dreyfuss, Francoise Leveil, Michel Paillard, Francoise Coste. Resetting of the vasopressin osmostat during infectious pneumonia. Am J Med.1991;90(3):407408. doi: https://doi.org/10.1016/0002-9343(91)80029-L.

7. Swart RM, Hoorn E J, Betjes MG, Zieste R. Hyponatremia and inflammation: the merging role of interleukin-6 in osmoregulation. Nephron Physiol.2011; 118(2):45-51. doi: 10.1159/000322238. Epub 2010 Dec 22

8. Charles R, Rees JR. Inappropriate secretion of antidiuretic hormone in pneumonia. Postgrad Med J. 1975;51(599):663-664. doi: 10.1136/pgmj.51.599.663.

9. Rahul V, Jose O. Prevalence of Hyponatremia in Children with Pneumonia. IOSR J Dent Med Sci. 2017; 16(3):46-50. doi: 10.9790/0853-1603044650

10. World Health Organization. Revised WHO Classification and Treatment of Pneumonia in Children at Health Facilities: Evidence Summaries. Geneva: World Health Organization; 2014. Available from: https://www. ncbi.nlm.nih.gov/ books/ NBK 264162/.

11. Mandal P, Garg M. To Study the association and significance of hyponatremia in pneumonia in paediatric patients treated in hospital setting. Int $\mathrm{J}$ Contemp Med Res. 2018;5(1):11-14.

12. Duru NS, Civilibal M, Bozdogan S, Elevli $M$. Hyponatremia in children hospitalized with pneumonia. J Pediatr Inf.2013; 7(3):102-105. doi: 10.5152/ced.2013.29.
13. Don M, Valerio G, Korppi M, Canciani M. Hyponatremia in pediatric community acquired pneumonia. Pediatr Nephrol. 2008;23 (12): 2247- 2253. doi: 10. 1007/s00467-008-0910-2.

14. Otheo E, Rodríguez M, Stanescu S, Coca A, Martín MD, González-Sainz $J$, et al. Hyponatremia is an inflammatory marker in children with Community Acquired Pneumonia. Clinic Infect Dis: Resp Infect. 2016; 3(1):1248. https:// doi.org/ 10.1093/ofid/ofw172.951.

15. Chaitra KM, Kumar MN, Reddy SG. Hyponatremia in lower respiratory tract infections. Int $\mathrm{J}$ Contemp Pediatr. 2016; 3(2):381-384. doi: http://dx.doi.org/10.18203/2349 - 3291.ijcp 20161018.

16. Singhi S, Dhawan A. Frequency and significance of electrolyte abnormalities in pneumonia. India Pediatr. 1992; 29(6):735-740.

17. Nair V, Nierdman MS, Masani N, Fishbane S. Hyponatremia in community acquired pneumonia. Am J Nephrol. 2007;27(2):184-190. doi:10.1159/000100866.

18. Karki L, Thapa B, Sah MK. Hyponatremia in Patients with Community Acquired Pneumonia. JNMA J Nepal Med Assoc. 2016;54(202):67-71.

19. Guruswamy NT, Khan H, Hedge P. Correlation of hyponatremia in children presenting with acute lower respiratory tract infection in a tertiary care hospital. Int $\mathbf{J}$ Rec Trends Sci Technol. 2014;12(3):631-634.

20. Swart RM, Hoorn EJ, Betjes MG, Zietse R. Hyponatremia and inflammation: the emerging role of interleukin-6 in osmoregulation. Nephron physiol.2011; 118(2):p45-p51.doi:10.1159/000322238.

21. Tagarro A, Martín MD, Del-Amo N, Sanz-Rosa D, Rodríguez M, Galán JC, et al. Hyponatremia in children with pneumonia rarely means SIADH. Paediatr Child Health. 2018;23(7):e126-e133. doi: 10.1093/pch/pxy003. Epub 2018 Mar 21.

22. Hausman-Kedem M, Reif S, Danino D, Limor R, Grinspan ZM, Yerushalmi-Feler A, et al. Mechanism of hyponatremia in community acquired pneumonia: Does BNP play a causative role? Pediatric Emerg Care. 2018; 34(9):641-646. doi: 10.1097/PEC.0000000000000814.

\section{How to cite this article?}

C. K. Praneetha, Ahirrao V. S, K. Srinivasa, R. Premalatha, B. Ravichander. Hyponatremia in children of 2 months to 5 years of age with community acquired pneumonia and its correlation with severity of illness and outcome. Int J Pediatr Res.2019; 6(11): 561-566.doi:10.17511/ijpr.2019.i11.02 